\title{
Effects of long-term warming on the aboveground biomass and species diversity in an alpine meadow on the Qinghai-Tibetan Plateau of China
}

\author{
WEN Jing, QIN Ruimin, ZHANG Shixiong, YANG Xiaoyan, XU Manhou* \\ Taiyuan Normal University, Jinzhong 030619, China
}

\begin{abstract}
Ecosystems in high-altitude regions are more sensitive and respond more rapidly than other ecosystems to global climate warming. The Qinghai-Tibet Plateau (QTP) of China is an ecologically fragile zone that is sensitive to global climate warming. It is of great importance to study the changes in aboveground biomass and species diversity of alpine meadows on the QTP under predicted future climate warming. In this study, we selected an alpine meadow on the QTP as the study object and used infrared radiators as the warming device for a simulation experiment over eight years (2011-2018). We then analyzed the dynamic changes in aboveground biomass and species diversity of the alpine meadow at different time scales, including an early stage of warming (2011-2013) and a late stage of warming (20162018), in order to explore the response of alpine meadows to short-term (three years) and long-term warming (eight years). The results showed that the short-term warming increased air temperature by $0.31^{\circ} \mathrm{C}$ and decreased relative humidity by $2.54 \%$, resulting in the air being warmer and drier. The long-term warming increased air temperature and relative humidity by $0.19^{\circ} \mathrm{C}$ and $1.47 \%$, respectively, and the air tended to be warmer and wetter. The short-term warming increased soil temperature by $2.44^{\circ} \mathrm{C}$ and decreased soil moisture by $12.47 \%$, whereas the long-term warming increased soil temperature by $1.76^{\circ} \mathrm{C}$ and decreased soil moisture by $9.90 \%$. This caused the shallow soil layer to become warmer and drier under both short-term and long-term warming. Furthermore, the degree of soil drought was alleviated with increased warming duration. Under the long-term warming, the importance value and aboveground biomass of plants in different families changed. The importance values of grasses and sedges decreased by $47.56 \%$ and $3.67 \%$, respectively, while the importance value of weeds increased by $1.37 \%$. Aboveground biomass of grasses decreased by $36.55 \%$, while those of sedges and weeds increased by $8.09 \%$ and $15.24 \%$, respectively. The increase in temperature had a non-significant effect on species diversity. The species diversity indices increased at the early stage of warming and decreased at the late stage of warming, but none of them reached significant levels $(P>0.05)$. Species diversity had no significant correlation with soil temperature and soil moisture under both short-term and long-term warming. Soil temperature and aboveground biomass were positively correlated in the control plots $(P=0.014)$, but negatively correlated under the long-term warming $(P=0.013)$. Therefore, eight years of warming aggravated drought in the shallow soil layer, which is beneficial for the growth of weeds but not for the growth of grasses. Warming changed the structure of alpine meadow communities and had a certain impact on the community species diversity. Our studies have great significance for the protection and effective utilization of alpine vegetation, as well as for the prevention of grassland degradation or desertification in high-altitude regions.
\end{abstract}

Keywords: climate warming; long-term warming; species diversity indices; aboveground biomass; soil microclimate; correlation analysis; alpine meadows

*Corresponding author: XU Manhou (E-mail: xumanhou@163.com)

Received 2019-05-13; revised 2020-01-16; accepted 2020-01-23

C Xinjiang Institute of Ecology and Geography, Chinese Academy of Sciences, Science Press and Springer-Verlag GmbH Germany, part of Springer Nature 2020 
Citation: WEN Jing, QIN Ruimin, ZHANG Shixiong, YANG Xiaoyan, XU Manhou. 2020. Effects of long-term warming on the aboveground biomass and species diversity in an alpine meadow on the Qinghai-Tibetan Plateau of China. Journal of Arid Land, 12(2): 252-266. https://doi.org/10.1007/s40333-020-0064-z

\section{Introduction}

In the Fifth Assessment Report, the Intergovernmental Panel on Climate Change (IPCC, 2014) indicated that the global mean surface temperature had increased by $0.85^{\circ} \mathrm{C}$ from 1880 to 2012 (Qin and Thomas, 2014). It is an indisputable fact that the Earth has become warmer (Oreskes, 2004). Climate warming profoundly affects the structural characteristics and processes of grassland ecosystems (Jiang et al., 2017), which provide important ecosystem services (Oliver et al., 2015). It is of great importance to study the changes in plant biomass and species diversity and their significance under predicted future climate warming (Hautier et al., 2014, 2015).

As the product of the interaction between plant characteristics and habitats, aboveground biomass is a principal index that can be used to assess the structure and function of ecosystems and has a profound impact on grassland livestock husbandry (Wang and Zhou, 2004). It has become an important aspect of biomass research in community ecology. However, no consistent conclusion on the response of aboveground biomass to climate warming exists (Li et al., 2019). Previous findings can be loosely divided into four categories as follows: aboveground biomass increases with temperature (Welker et al., 1997; Sandvik et al., 2004), decreases with temperature (Boeck et al., 2007; Zong et al., 2016), increases at first but then decreases with temperature (Li et al., 2004), and does not change with temperature (Kudo and Suzuki, 2003; Jiang et al., 2017). In addition, the response of aboveground biomass of different plants to climate warming is also varied (Walker et al., 2006; Prieto et al., 2009; Lin et al., 2010). Studies on alpine meadows showed that aboveground biomass of grasses and sedges increases after warming, while that of weeds decreases (Zhou et al., 2000). However, other studies have found that aboveground biomass of grasses and sedges decreases under the warming condition, and weeds become the dominant species in the community (Li et al., 2017). As the effect of temperature on aboveground biomass of different functional plant groups is still unclear, it is necessary to explore the impact of the biomass of different plant functional types on simulated warming to understand the response of plant community productivity under climate warming and to accurately evaluate ecosystem productivity (Oliver et al., 2015; Ma et al., 2017).

Species diversity, an important research component of biodiversity, plays a vital role in maintaining the stability of the Earth's ecosystem and providing ecosystem services (Klein et al., 2004). Exploring the variation trends in species diversity in the context of climate warming is of great scientific significance for evaluating the change and succession of plant community structure. The response of species diversity to warming is fairly time-dependent. Studies have shown that different warming durations have different impacts on species diversity (Ma et al., 2017). Species diversity was not sensitive to warming in a three-year simulated warming experiment in an alpine meadow (Xu et al., 2015a), whereas five years of simulated warming reduced species diversity (Li et al., 2004), and 16 years of warming increased species diversity slightly (Zhao et al., 2015). Zhao et al. (2003) found that species diversity increased in the first two years of warming, but decreased in the third year of warming due to decreased soil moisture. The hydrothermal environmental factors changed under the warming treatment, which affected the soil nutrient content (Zhao et al., 2015), making the relationship between environmental factors and species diversity more complex. The relationships between environmental factors and species diversity under the warming treatment have been little studied, and the mechanisms remain to be further explored (Wang et al., 2013).

The terrestrial ecosystem is significant for maintaining the stability and productivity of the grassland ecosystem (Zhao et al., 2004). The Qinghai-Tibet Plateau (QTP) of China is an ecologically fragile zone that is sensitive to global climate warming, and constitutes an ideal region for studying the response mechanisms of terrestrial ecosystems to climate warming (Qiu, 2008; Yin et al., 2008). The vegetation on the QTP is very sensitive to climate warming (Shi et 
al., 2008). Alpine meadows, a typical vegetation type on the QTP, are a unique result of the adaptation to plateau uplift and the formation of a long-term low-temperature environment. They comprise typical plateau zonal and mountainous vertical zonal vegetation, and their ecosystems are extremely fragile and sensitive to the impacts of climate change and human activities (Zhou et al., 2000). Alpine meadows are a vegetation type that developed in the permafrost regions of the QTP. The melting of frozen soil can significantly affect the growth and development of meadow plants under climate warming, thus changing the structure and biomass characteristics of meadow communities (Xu et al., 2016). As the climate gets warmer, alpine meadows have shown a significant degradation trend, particularly under human disturbance (Lu et al., 2015), and both the biomass and diversity of alpine meadows are declining. Therefore, assessing the impact of climate warming on alpine meadow ecosystems is important for the conservation of species diversity and the rational utilization of grasslands on the QTP.

Given the uncertainty of the responses of biomass and species diversity to increased temperature, infrared radiators were used in the present study as the warming device to simulate warming over eight years. An alpine meadow on the QTP was selected as the research object, and the vegetation was divided into three categories: grasses, sedges and weeds. Then, we analyzed the dynamic changes of aboveground biomass and species diversity of plants at different time scales, including the early stage of warming (2011-2013) and the late stage of warming (20162018), to further interpret the effects of warming on: (1) the environmental factors of alpine meadows; (2) the species diversity and aboveground biomass of alpine meadows; and (3) the relationship of soil hydrothermal factors with species diversity and aboveground biomass. Our findings are expected to provide theoretical support for the protection and rational use of alpine vegetation in high-altitude areas by elucidating the responses of aboveground biomass and species diversity to short-term and long-term warming.

\section{Study area and methods}

\subsection{Study area}

The study area is located at the Beiluhe Permafrost Field Station of Chinese Academy of Sciences $\left(34^{\circ} 49^{\prime} 34^{\prime \prime}-34^{\circ} 49^{\prime} 37^{\prime \prime} \mathrm{N}, 92^{\circ} 55^{\prime} 57^{\prime \prime}-92^{\circ} 56^{\prime} 06^{\prime \prime} \mathrm{E}\right.$; $4633.5 \mathrm{~m}$ a.s.l.; Fig. 1a) on the QTP, China. The site is in an arid and cold area with an annual mean temperature of $-5.9^{\circ} \mathrm{C}$, a mean annual precipitation of $267.6 \mathrm{~mm}$ and a mean annual potential evaporation of $1316.9 \mathrm{~mm}$. Located in the permafrost region, it freezes from September to April, and thus, the growing season is from May to September. The vegetation at this site is alpine meadow. In the growing season, the alpine meadow, with a vegetation coverage of $83 \%$, is dominated by Cyperaceae and Compositae, and some Leguminosae can also be found. Of this vegetation, Kobresia pygmaea (Cyperaceae) is the constructive species and is accompanied by Carex moorcroftii (Cyperaceae), Oxytropis pusilla (Leguminosae), Androsace tapete (Primulaceae), Leontopodium nanum (Compositae) and Saussurea pulchra (Compositae). Polygonum viviparum (Polygonaceae) is also common in the study site (Xu and Xue, 2013; Xu et al., 2015a, b, 2016).

\subsection{Experimental design}

The experimental plot is located in a typical alpine meadow area about $300 \mathrm{~m}$ away from the Beiluhe Permafrost Field Station of Chinese Academy of Sciences. The terrain is relatively flat. The vegetation is well-distributed and is not disturbed by grazing or by pikas. The experiment was designed as a randomized block. There were five blocks in the experiment and each block had two treatments: control and warming $\left(150 \mathrm{~W} / \mathrm{m}^{2}\right.$; Fig. 1b). There were 10 plots in total (area of $2 \mathrm{~m} \times 2 \mathrm{~m}$ for each plot) and the distance between adjacent plots was 4-5 $\mathrm{m}$ (Xu et al., 2015a, b, 2016; Fig. 1c). In the control plots, there was no warming treatment, and the natural state of the vegetation was maintained. In the warming plots, infrared radiators (Kalglo Electronics, Bethlehem, PA, USA) were used as the warming device to simulate warming. The lamp body is a triangular prism with a length of $165 \mathrm{~cm}$ and a width of $15 \mathrm{~cm}$, and the lamp tube is a cylinder with a length of $150 \mathrm{~cm}$ and a diameter of $8 \mathrm{~mm}$. The reflector surface of the radiator was 
suspended at $1.5 \mathrm{~m}$ above the warming plots. The outer circumference of each group was surrounded by wire mesh to prevent damage.

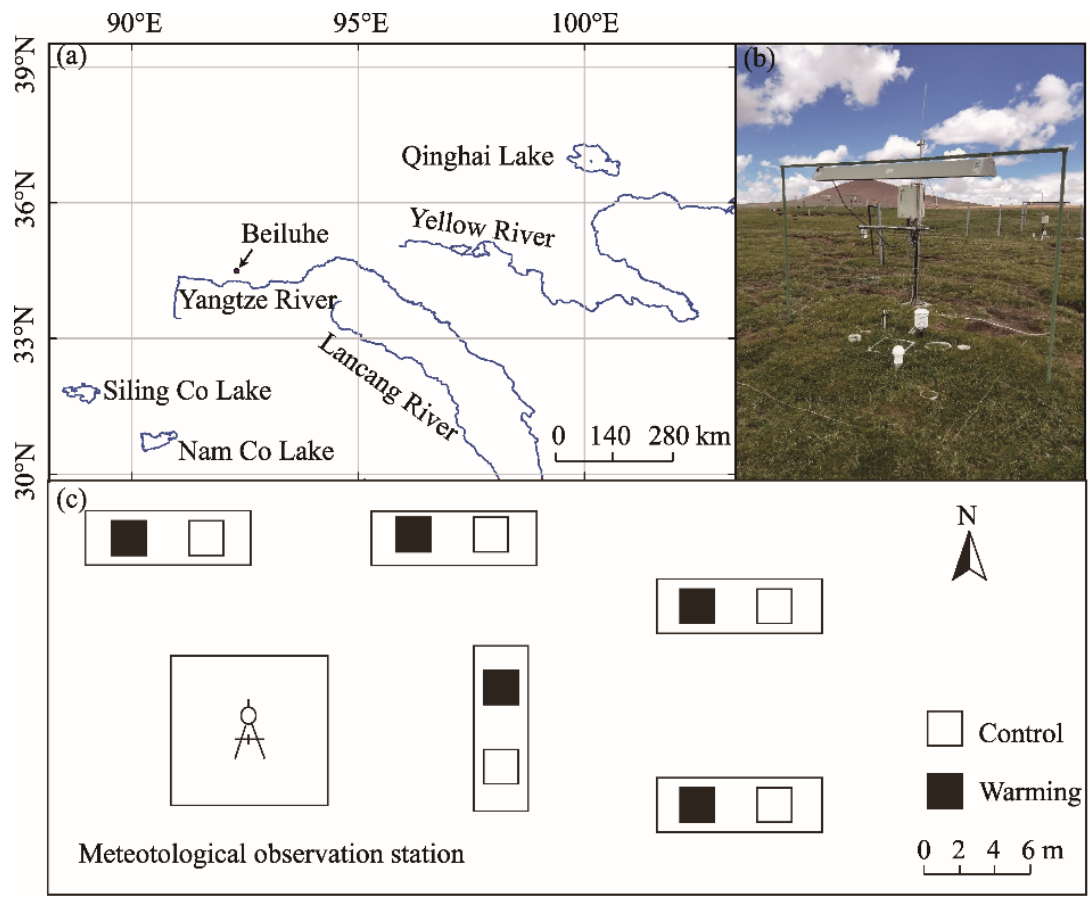

Fig. 1 Location of the study area on the Qinghai-Tibetan Plateau, China (a), a photograph of the warming plot (b) and the design of experimental plots (c)

\subsection{Measurements of temperature and moisture}

The warming treatment lasted for eight years (from July 2010 to October 2018), and uninterrupted warming was applied throughout the whole year. Due to a lack of some data in 2013, 2014 and 2015, we selected the temperature and moisture data collected in 2011, 2012, 2016, 2017 and 2018 for analysis. Air temperature and relative humidity were assessed at $20 \mathrm{~cm}$ from the land surface; soil temperature was determined at $5 \mathrm{~cm}$ soil depth; and soil moisture was assessed at $10 \mathrm{~cm}$ soil depth. Air temperature and relative humidity were measured using a HMP45C temperature and humidity sensor, which was placed inside a radiation shield to avoid the influence of upstream and downstream radiation on temperature. Soil temperature was measured with a 109 SS-L temperature sensor and soil moisture was measured with an Envior SMART moisture sensor. All sensors were connected to a CR1000 data collector, and the average data were recorded every $10 \mathrm{~min}$ for data analysis. All the sensors and the data collector were produced by the Campbell Scientific Inc., Logan, USA.

\subsection{Measurements of plant characteristics}

Plant characteristics were investigated in early September in 2011, 2012, 2013, 2016, 2017 and 2018. As no vegetation data were collected in 2014 and 2015, the data collected were divided into two stages on a three-year scale: the early stage of the experiment (2011-2013) and the late stage of the experiment (2016-2018). For the plant characteristics, the species name, height, coverage, frequency, abundance and aboveground biomass were recorded. The plant characteristics were measured using an aluminum frame with a size of $27 \mathrm{~cm} \times 27 \mathrm{~cm}$. The frame was divided into 100 grids by a wire mesh, and the area of each grid was $2.5 \mathrm{~cm} \times 2.5 \mathrm{~cm}$. Firstly, we determined the characteristics of each species in the frame, and the species diversity indices were then calculated using the characteristic values. We then selected some temporary plots around the experimental plots (control and warming). The plant height and coverage in the temporary plots were consistent with the experimental plots. The aboveground biomass of the temporary plots was harvested, 
transported to the laboratory, placed into an oven and dried for $24 \mathrm{~h}$ to a constant weight at $75^{\circ} \mathrm{C}$, and then weighed. Finally, a stepwise regression equation was established using the height, coverage and aboveground biomass of the plants in the temporary plots, and the aboveground biomass in the experimental plots was indirectly obtained.

\subsection{Data analysis}

This study used five years of environmental data (2011, 2012, 2016, 2017 and 2018) and six years of plant data $(2011,2012,2013,2016,2017$ and 2018) for multivariate analysis of variance, and used five years of environmental and plant data $(2011,2012,2016,2017$ and 2018) for correlation analysis. The processing of plant data includes the calculations of aboveground biomass, importance value and species diversity.

Firstly, as the warming experiment was designed for the long term, we thus selected 100 temporary plots with similar plant height and coverage around the experimental plots to estimate the aboveground biomass on the experimental plots (Xu et al., 2015a). The plant aboveground biomass data were calculated by establishing a stepwise regression equation among plant height, coverage and aboveground biomass in SPSS 19.0 software (IBM Corp., Armonk, USA).

$$
\mathrm{AGB}=308.26 c+22.764 h-121.801 \quad\left(R^{2}=0.737 ; P<0.001 ; n=100\right),
$$

where, AGB is the plant aboveground biomass $\left(\mathrm{g} / \mathrm{m}^{2}\right) ; c$ is the plant coverage (fractional representation); $h$ is the plant height $(\mathrm{cm})$; and $n$ is the total number of temporary plots.

Secondly, by referring to the scientific names and taxonomic information in Flora of China (http://www.iplant.cn/foc/), we classified all the plant species into three types according to the definition of plant functional types: grasses (Gramineae species), sedges (Cyperaceae species) and weeds (except for Gramineae and Cyperaceae species) (Peng et al., 2017; Xu et al., 2020). We calculated the importance value of plant species according to the height, density, coverage and frequency of each species in each plant functional type in order to indicate its position and function in the plant community. In this study, we focused on plants in the same habit, and thus calculated the $\alpha$-diversity indices, including the Margalef index, Simpson index, Shannon-Weiner index and Pielou index (Xu et al., 2015a). These indices were calculated using the following formulas (Agrawal and Gopal, 2013) in Microsoft Office Excel 2016.

$$
\begin{gathered}
\mathrm{IV}=\frac{\mathrm{RH}+\mathrm{RD}+\mathrm{RC}+\mathrm{RF}}{4}, \\
H^{\prime}=1-\sum_{i=1}^{S} P_{i}^{2}, \\
H=-\sum_{i=1}^{S} P_{i} \ln \left(P_{i}\right), \\
E=\frac{H}{\ln (S)}, \\
R=S,
\end{gathered}
$$

where, IV is the importance value; $\mathrm{RH}$ is the relative height; $\mathrm{RD}$ is the relative density; $\mathrm{RC}$ is relative coverage; RF is the relative frequency; $H^{\prime}$ is the Simpson index; $S$ is the total number of plant species in each plot; $i$ is the plant species; $P_{i}$ is the relative importance value of species $i$ in each plot; $H$ is the Shannon-Weiner index; $E$ is the Pielou index; and $R$ is the Margalef index.

Finally, the General Linear Model in SPSS 23.0 (IBM Corp., Armonk, USA) was used for multi-way analysis of variance with the following aims: (1) to analyze air temperature, relative humidity, soil temperature and soil moisture among different treatments, years and months; (2) to analyze plant height, frequency, coverage, density, importance value and aboveground biomass among different treatments, years and families; and (3) to analyze species diversity indices between different years and different treatments. Bivariate correlation in SPSS 23.0 was used to analyze the correlation between soil microclimate (soil temperature and soil moisture) and species 
diversity and aboveground biomass. Using OriginPro 9.1 software (OriginLab Corp., Hampton, MA, USA), we draw the line graphs and column graphs to analyze the variations of environmental factors and plant communities under different treatments and years.

\section{Results}

\subsection{Changes in the microclimate}

\subsubsection{Air temperature and relative humidity}

In the growing season, air temperature varied significantly among different years $(P<0.01$; Table 1). In the warming plots, air temperature increased by $0.31^{\circ} \mathrm{C}$ from 2011 to 2012 , and increased by $0.12^{\circ} \mathrm{C}$ from 2016 to 2018 . The simulated warming increased air temperature by $0.19^{\circ} \mathrm{C}$ in eight years (2011-2018), and the warming effect showed a significant yearly downward trend. Air temperature also varied significantly with the month $(P<0.01)$, and temperatures in July and August were significantly higher than those in the other months (Fig. 2). The difference in air temperature among different treatments was not significant $(P=0.054)$, but did reach a significant level with the interaction of treatments and years $(P=0.038)$.

In the growing season, the variations in relative humidity under different treatments and different years reached significant levels $(P=0.037$ and $P=0.016$, respectively; Table 1$)$. In the warming plots, relative humidity decreased by $2.54 \%$ from 2011 to 2012 and increased by $4.20 \%$ from 2016 to 2018 . Relative humidity of the air increased by $1.47 \%$ on average in eight years (from 2011 to 2018). It increased significantly with the year and also varied significantly among different months $(P<0.01)$. In particular, relative humidity in May was significantly lower than those in the other months (Fig. 2).

Table 1 Multi-way ANOVA of air temperature and relative humidity in different treatments, years and months

\begin{tabular}{cccccccc}
\hline Item & $\mathrm{T}$ & $\mathrm{Y}$ & $\mathrm{M}$ & $\mathrm{T} \times \mathrm{Y}$ & $\mathrm{T} \times \mathrm{M}$ & $\mathrm{Y} \times \mathrm{M}$ & $\mathrm{T} \times \mathrm{Y} \times \mathrm{M}$ \\
\hline Air temperature & 0.054 & 0.000 & 0.000 & 0.038 & 0.294 & 0.000 & 0.560 \\
Relative humidity & 0.037 & 0.016 & 0.000 & 0.037 & 0.795 & 0.143 & 0.998 \\
\hline
\end{tabular}

Note: T, treatment; Y, year; M, month.
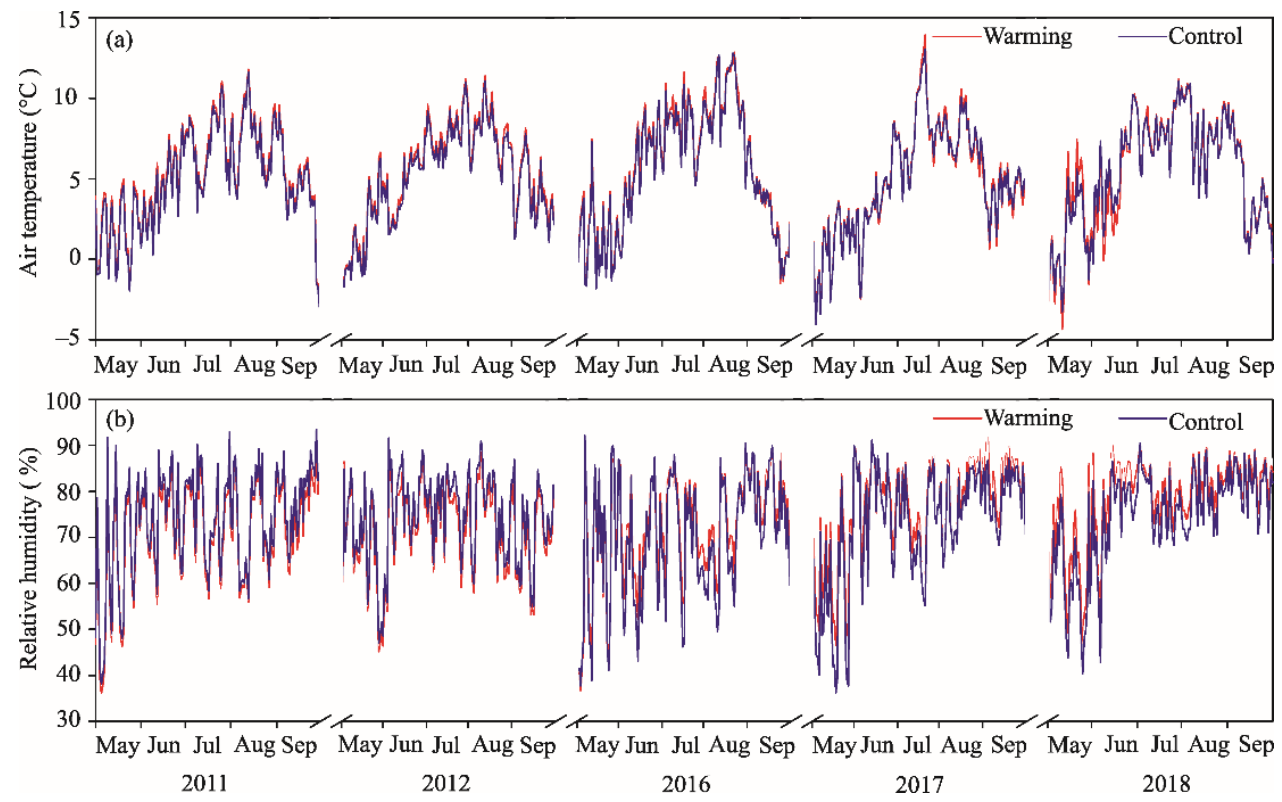

Fig. 2 Variations in air temperature (a) and relative humidity (b) in the growing season (from May to September) in different years and under different treatments. The shaded areas indicate standard errors $(n=5)$.

In general, air temperature and relative humidity varied little among different treatments in the 
growing season. In the early stage of warming (2011-2013), air temperature increased and relative humidity decreased, and the air tended to be warmer and drier. In the late stage of warming (2016-2018), both the air temperature and relative humidity increased, and the air tended to be warmer and wetter. Over eight years of warming, the air generally tended to be warmer and wetter.

\subsubsection{Soil temperature and soil moisture}

In the growing season, soil temperature differed significantly under different treatments $(P<0.01$; Table 2). Warming increased surface soil temperature by $2.44^{\circ} \mathrm{C}$ in the early stage and $1.30^{\circ} \mathrm{C}$ in the late stage. The eight years of warming increased surface soil temperature by $1.76^{\circ} \mathrm{C}$ and the warming effect decreased significantly year by year. Soil temperature also varied significantly among different months $(P<0.01)$, and soil temperatures in July and August were significantly higher than those in the other months (Fig. 3).

In the growing season, warming decreased soil moisture by $12.47 \%$ in the early stage and $8.08 \%$ in the late stage. The eight years of warming decreased soil moisture by $9.90 \%$, with soil moisture decreasing yearly. In terms of months, soil moisture differed significantly among different months $(P=0.015$; Table 2$)$, and soil moisture contents in August and September were significantly higher than those in the other months (Fig. 3).

In general, warming led to the evaporation of soil water, which tends to make the soil environment warmer and drier. In the early stage of warming, the increase in soil temperature was relatively small, the decrease in soil moisture was relatively large, and the drought degree of the soil environment was aggravated. In the late stage of warming, soil temperature increased greatly, the decrease in soil moisture was relatively small, and the drought of the soil environment was alleviated.

Table 2 Multi-way ANOVA of soil temperature and soil moisture in different treatments, years and months

\begin{tabular}{cccccccc}
\hline Item & $\mathrm{T}$ & $\mathrm{Y}$ & $\mathrm{M}$ & $\mathrm{T} \times \mathrm{Y}$ & $\mathrm{T} \times \mathrm{M}$ & $\mathrm{Y} \times \mathrm{M}$ & $\mathrm{T} \times \mathrm{Y} \times \mathrm{M}$ \\
\hline Soil temperature & 0.002 & 0.119 & 0.000 & 0.280 & 0.955 & 0.615 & 0.994 \\
Soil moisture & 0.277 & 0.223 & 0.015 & 0.977 & 0.995 & 0.933 & 1.000 \\
\hline
\end{tabular}

Note: T, treatment; Y, year; M, month.
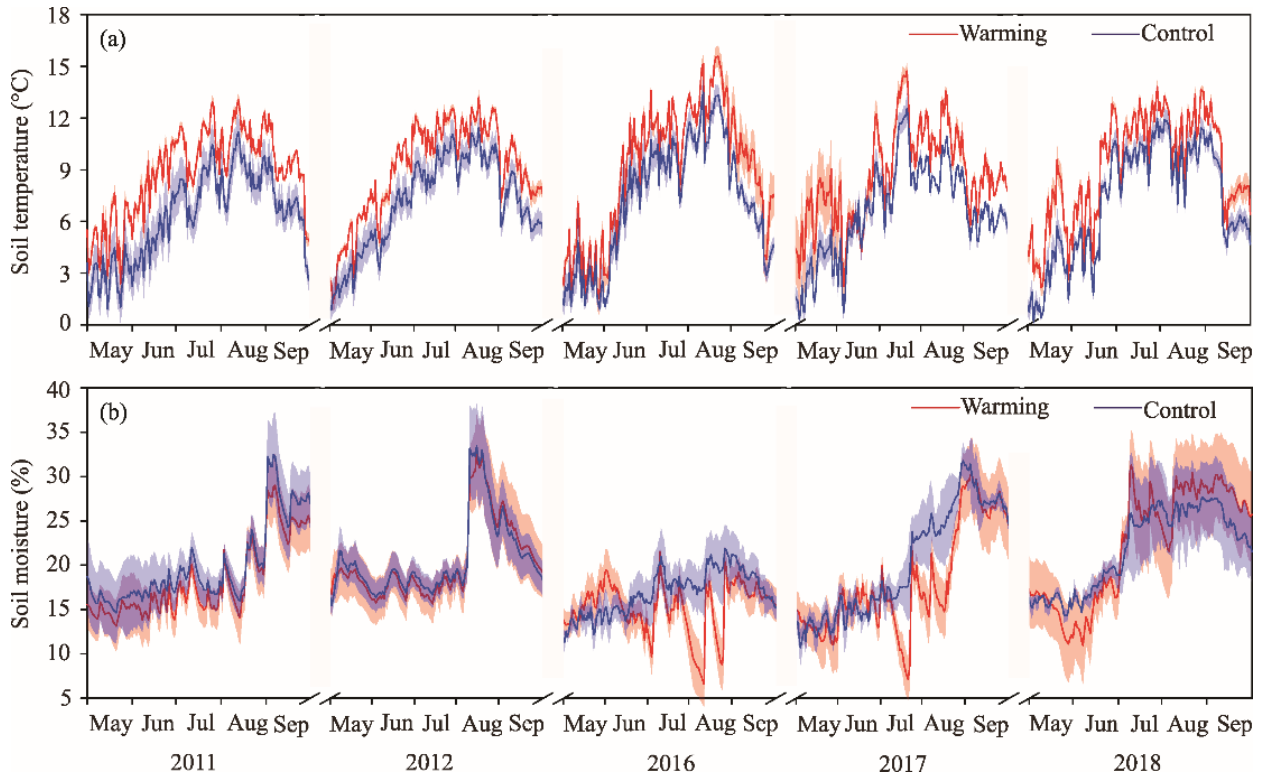

Fig. 3 Variations in soil temperature (a) and soil moisture (b) in the growing season (from May to September) in different years and under different treatments. The shaded areas indicate standard errors $(n=5)$.

\subsection{Species diversity}

In the experimental plots, we identified a total of 39 plant species, belonging to 11 families and 
22 genera. We divided them into three categories according to their functional types: grasses (seven species belonging to six genera of Gramineae), sedges (six species belonging to two genera of Cyperaceae) and weeds (26 species belonging to 14 genera of nine families). As far as the families of weeds, they are Asteraceae, Leguminosae, Polygonaceae, Rosaceae, Cruciferae, Primulaceae, Ranunculaceae, Scrophulariaceae and Saxifragaceae.

Under the warming treatment, the importance values of grasses and sedges decreased by $47.56 \%$ and $3.67 \%$, respectively, and the importance value of weeds increased by $1.37 \%$. However, the change did not reach significant levels among different treatments $(P>0.05$; Table $3)$. Significant differences of importance value were found between different years and different families $(P<0.01)$, and the changes under the combined action of the two were also significant $(P<0.05)$. From 2011 to 2013 , warming decreased the importance values of grasses and sedges by $56.56 \%$ and $9.87 \%$, respectively, while warming increased the importance value of weeds by $1.57 \%$. From 2016 to 2018 , the importance value of grasses decreased by $35.69 \%$, whereas the importance values of sedges and weeds increased by $5.21 \%$ and $1.08 \%$, respectively (Fig. 4).

There was no significant difference in the species diversity indices among different treatments (Table 3). From 2011 to 2013, warming increased the Simpson index, Shannon-Wiener index, Pielou index and Margalef index by 5.69\%, 8.43\%, 3.71\% and 5.26\%, respectively. From 2016 to 2018, warming decreased the Simpson index, Shannon-Wiener index and Pielou index by 3.94\%, $3.05 \%$ and $4.48 \%$, respectively, while the Margalef index did not change. The eight years of warming increased the Simpson index, Shannon-Wiener index and Margalef index by $0.66 \%$, $2.22 \%$ and $2.27 \%$, respectively (Fig. 5), and the three diversity indices differed significantly among different years $(P<0.05)$. The Pielou index decreased by $0.40 \%$ under the eight years of warming condition, and there was no significant difference of the Pielou index among different years $(P=0.177)$.

Overall, during the warming period, the importance value of grasses decreased and that of weeds increased, indicating that warming did not render the environment conducive to the growth of grasses, and this vegetation type might ultimately have been replaced by weeds. The species diversity indices increased in the early stage of warming and decreased in the late stage of warming, indicating that the long-term warming reduced the species diversity, but the difference was not significant among different treatments.

Table 3 Multi-way ANOVA of vegetation importance value, species diversity indices and aboveground biomass in different treatments, years and families

\begin{tabular}{cccccccc}
\hline Item & $\mathrm{T}$ & $\mathrm{Y}$ & $\mathrm{F}$ & $\mathrm{T} \times \mathrm{Y}$ & $\mathrm{T} \times \mathrm{F}$ & $\mathrm{Y} \times \mathrm{F}$ & $\mathrm{T} \times \mathrm{Y} \times \mathrm{F}$ \\
\hline Importance value & 0.098 & 0.000 & 0.000 & 0.793 & 0.604 & 0.019 & 0.892 \\
Simpson index & 0.774 & 0.000 & & 0.236 & & & \\
Shannon-Weiner index & 0.511 & 0.000 & & 0.566 & & & \\
Margalef index & 0.763 & 0.000 & & 0.996 & & & \\
Pielou index & 0.885 & 0.177 & & 0.307 & & & 0.315 \\
Aboveground biomass & 0.826 & 0.164 & 0.000 & 0.570 & 0.332 & 0.962 \\
\hline
\end{tabular}

Note: T, treatment; Y, year; F, family.

\subsection{Aboveground biomass}

Under the warming treatment, aboveground biomass of grasses decreased by $36.55 \%$; aboveground biomasses of sedges and weeds increased by $8.09 \%$ and $15.24 \%$, respectively; and the total aboveground biomass increased by $13.61 \%$ (Fig. 6). Aboveground biomass differed significantly among different families $(P<0.01)$, but did not reach significant levels between treatments $(P>0.05$; Table 3$)$. In terms of the year, from 2011 to 2013, aboveground biomass of grasses decreased by $52.9 \%$; aboveground biomasses of sedges and weeds increased by $4.59 \%$ and $12.85 \%$, respectively; and the total aboveground biomass increased by $17.17 \%$. From 2016 to 2018, aboveground biomass of grasses decreased by 19.00\%; aboveground biomasses of sedges and weeds increased by $11.09 \%$ and $17.30 \%$, respectively; and the total aboveground biomass increased by $11.40 \%$. Aboveground biomass changed with the year, but the difference was not 
significant $(P=0.164$; Table 3$)$.

Overall, warming increased aboveground biomass in the experimental plots. During the warming period, aboveground biomasses of sedges and weeds increased, while aboveground biomass of grasses decreased significantly, indicating that warming changed the biomass distribution of alpine meadows, thus altering the community structure.

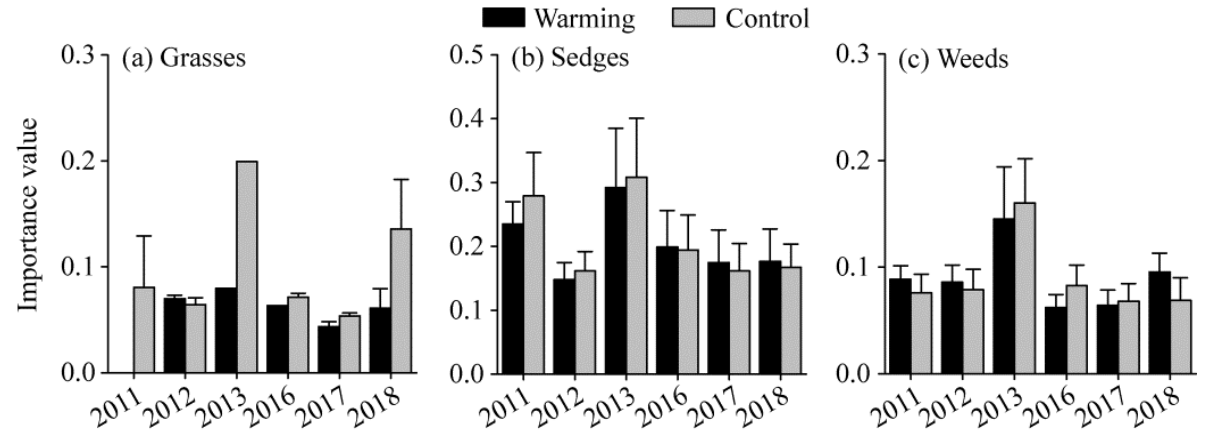

Fig. 4 Variations in importance values of grasses (a), sedges (b) and weeds (c) in different years and under different treatments. The error bars indicate standard errors $(n=3)$. It should be noted that grasses were not appeared under the warming treatment in 2011.

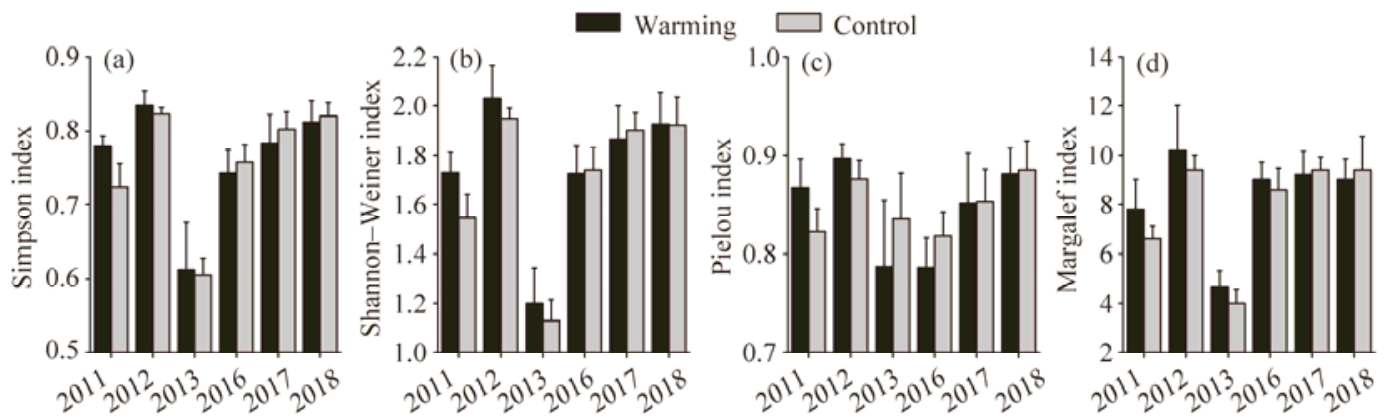

Fig. 5 Variations in species diversity indices in different years and under different treatments. (a), Simpson index; (b), Shannon-Weiner index; (c), Pielou index; (d), Margalef index. The error bars indicate standard errors $(n=3)$.

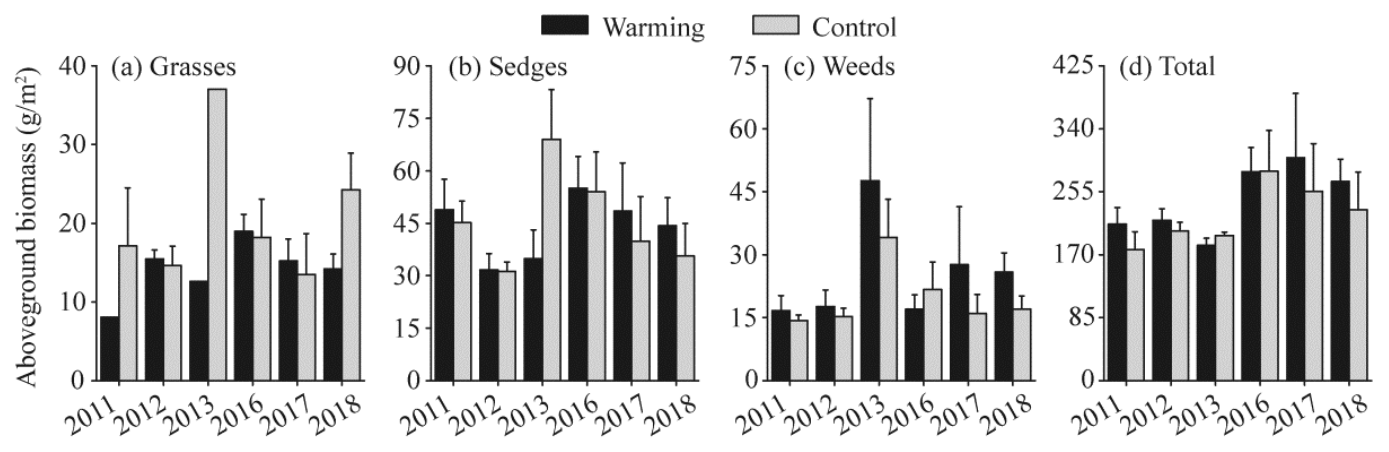

Fig. 6 Variations in aboveground biomass of grasses (a), sedges (b) and weeds (c) and the total aboveground biomass (d) in different years and under different treatments. The error bars indicate standard errors $(n=3)$. It should be noted that grasses did not appear in the warming plots in 2011.

\subsection{Correlation analysis of soil microclimate with species diversity and aboveground biomass}

A correlation analysis of soil microclimate factors (soil temperature and soil moisture) with species diversity indices and aboveground biomass was carried out under the short-term and long-term warming conditions (Table 4). There was no significant correlation between species diversity indices and soil microclimate factors (soil temperature and soil moisture) under both 
short-term and long-term warming, and their relationship was mainly affected by time factors. In the early stage of warming, the correlation was not significant. At an eight-year time scale of warming, soil temperature was positively correlated with the Shannon-Weiner index $(r=0.385$, $P=0.043)$ and Margalef index $(r=0.481, P=0.027)$, but soil moisture was negatively correlated with the Shannon-Weiner index $(r=0.417, P=0.027)$ and Margalef index $(r=0.414, P=0.029)$.

Under warming conditions, soil temperature had a significant correlation with aboveground biomass. There was a positive correlation between soil temperature and aboveground biomass in the control plots $(r=0.660, P=0.014)$, but there was a negative correlation in the warming plots, especially under the long-term warming condition $(r=-0.464, P=0.013)$.

Short-term and long-term warming typically had different effects on the relationship between soil microclimate and plants. In general, there was no correlation between soil microclimate factors and species diversity indices under warming conditions. Aboveground biomass was significantly related to soil temperature, and the amount of aboveground biomass decreased with increase of soil temperature.

Table 4 Correlation analysis of soil microclimate factors (soil temperature and soil moisture) with species diversity indices (Simpson index, Shannon-Weiner index, Margalef index and Pielou index) and aboveground biomass at different warming time scales and under different treatments

\begin{tabular}{|c|c|c|c|c|c|}
\hline \multirow{2}{*}{ Warming time scale } & \multirow{2}{*}{ Item } & \multicolumn{2}{|c|}{ Soil temperature } & \multicolumn{2}{|c|}{ Soil moisture } \\
\hline & & Control & Warming & Control & Warming \\
\hline \multirow{5}{*}{$\begin{array}{l}\text { Short-term warming } \\
\text { (three years) }\end{array}$} & Simpson index & 0.246 & 0.143 & -0.301 & -0.223 \\
\hline & Shannon-Weiner index & 0.244 & 0.212 & -0.282 & -0.287 \\
\hline & Margalef index & 0.245 & 0.287 & -0.251 & -0.376 \\
\hline & Pielou index & 0.123 & -0.127 & -0.138 & -0.084 \\
\hline & Aboveground biomass & $0.660^{*}$ & -0.287 & -0.359 & 0.406 \\
\hline \multirow{5}{*}{$\begin{array}{l}\text { Long-term warming } \\
\text { (eight years) }\end{array}$} & Simpson index & 0.298 & 0.144 & -0.355 & -0.304 \\
\hline & Shannon-Weiner index & $0.385^{*}$ & 0.159 & $-0.417^{*}$ & -0.326 \\
\hline & Margalef index & $0.418^{*}$ & 0.195 & $-0.414^{*}$ & -0.315 \\
\hline & Pielou index & 0.030 & 0.020 & -0.074 & -0.217 \\
\hline & Aboveground biomass & 0.296 & $-0.464^{*}$ & -0.028 & 0.178 \\
\hline
\end{tabular}

Note: ${ }^{*}, P<0.05$ level.

\section{Discussion}

\subsection{Effects of warming on the microclimate}

Infrared radiator is an ideal device to simulate warming. It can realistically simulate the warming mechanism and daily variation in global climate warming and has little physical interference to the vegetation and soil (Hou et al., 2013). The infrared radiator can achieve uniform and controllable heating effects, particularly for low-canopy vegetation (Kimball et al., 2007).

The results in this study showed that eight years of warming increased the air temperature by $0.19^{\circ} \mathrm{C}$ and the relative humidity by $1.47 \%$. Overall, warming made the air warmer and wetter. According to the study of $\mathrm{Wu}$ et al. (2005), data collected from 77 meteorological stations on the Tibetan Plateau showed that the main trends of climate change included increased temperature and increased precipitation, with most of the areas tending to change from dry to wet. However, some controversy still exists regarding whether infrared radiators can increase the air temperature (Hou et al., 2013). In this study, air temperature increased by $0.19^{\circ} \mathrm{C}$ after eight years of warming, which is a relatively small increase. This may be related to the type of the ecosystem and other environmental factors studied, such as the wind speed (Niu et al., 2007). The increase in relative humidity may be related to surface evapotranspiration. Wan et al. (2002) suggested that infrared radiators could directly heat the vegetation canopy and soil, thereby causing an increase in the evaporation of plants and soil and leading to a decrease in soil moisture. In their test, soil moisture decreased by $8.74 \%$. Shi et al. (2008) used an open top chamber (OTC) to simulate 
warming and the results showed that the warming effect of the OTC directly led to a decrease in soil moisture in the OTC. This indicated that both the active warming of the infrared radiator and the passive warming of the OTC resulted in a decrease in shallow soil moisture, and that the soil environment tended to be warmer and drier.

\subsection{Effects of warming on the plant community}

In this study, the effects of short-term and long-term warming on the different plant families were studied in two stages: the early stage of warming (2011-2013) and the late stage of warming (2016-2018). Due to the complexity of the alpine meadow ecosystem, the sensitivity of different plants to temperature is different, and it is difficult to accurately assess the response and adaptation of the ecosystem to climate change under the short-term warming. Plants and their communities have a lagging response to the long-term effects of resource feedback, growth and competition. The response of long-term warming may be limited by environmental factors, such as water and nutrient, which make the long-term and short-term responses of plants or plant communities to warming being different (Niu et al., 2007).

Climate change, which is the primary natural factor affecting biodiversity, determines species distribution and vegetation types. Changes in climate factors will lead to variations in species diversity (Ma et al., 2017). Our study found that species diversity in the warming plots was higher than that in the control plots from 2011 to 2013, while species diversity in the control plots was higher than that in the warming plots from 2016 to 2018. Zhao et al. (2003) found that species diversity increased in the first two years of warming, but decreased in the third year of warming. Li et al. (2004) found that species diversity of a Kobresia humilis meadow decreased after five years of warming compared with the control plots. After eight years of warming, our study found that species diversity indices changed little, particularly the Margalef index, and that there was no significant difference of species diversity indices between different treatments. In an eight-year warming experiment, Yang et al. (2017) also revealed that species diversity fluctuated within a relatively small range regardless of nighttime warming or daytime warming. This shows that the effect of eight-year warming on the species diversity is still small, and thus, a significant response of species diversity to warming may require a longer time scale. The results of a 14-year warming experiment showed that species diversity decreased in the $8^{\text {th }}$ year, which was mainly due to the negative competition of invasive species and dominant species, indicating that the long-term warming could alter the grassland community structure (Shi et al., 2015).

In the context of global climate warming, for any plant community, there are always some species that are more sensitive to temperature increases than others, and thus they could alter the interspecific competition and cause changes in the dominant species and community composition (Alward et al., 1999; Pauli et al., 2001). In this study, grasses had the most sensitive response to warming during the experiment, and aboveground biomass of which showed a downward trend. In contrast, aboveground biomass of weeds showed an upward trend, which indicated that warming made the growth environment more conducive to the growth of weeds, and that grasses were gradually replaced by weeds. Li and Liu (2017) found that the long-term warming in an alpine meadow was associated with a change in the community dominance: the proportion of fine forage grasses (grasses and sedges) was decreased, and weeds gradually became the dominant community. However, in the study of Zhou et al. (2000), aboveground biomasses of grasses and sedges increased, while aboveground biomass of weeds decreased in the Haibei Alpine Meadow Ecosystem Research Station (Qinghai Province of China). This is inconsistent with the conclusions of this study, which may be related to the warming time and the environmental conditions of the study area. Specifically, the research conducted by Zhou et al. (2000) was based on one-year warming data, whereas this study was based on eight-year warming data. The difference in warming time period will lead to different responses. The altitude of the Haibei Alpine Meadow Ecosystem Research Station is 3200-3600 m a.s.l., and the constructive species include grass plants. In contrast, the altitude of the Beiluhe Permafrost Field Station of Chinese Academy of Sciences (our study site) is 4620-4630 m a.s.l., and the constructive species are sedges. Different altitudes lead to different climatic environments, and the adaptation of the vegetation to different 
environments also exhibits differences. Zhou et al. (2000) also noted that the main cause of aboveground biomass change was the biological characteristics of the various grasses and the differences in resource utilization. Other environmental factors in addition to temperature may also impact these characteristics.

\subsection{Effects of warming on the relationship of soil microclimate with species diversity and aboveground biomass}

The adaptation of plants to the environment is reflected by the change of individual characteristics and is ultimately reflected by the species diversity. This study found that species diversity was positively correlated with soil temperature and negatively correlated with soil moisture. Wu et al. (2012) showed that species diversity was negatively correlated with soil temperature and positively correlated with soil moisture. Yang et al. (2016) had a similar conclusion. This differs from the result of this study, as our study area is in the permafrost region of the QTP. The permafrost results in the correlation between species diversity and soil temperature being higher than that between species diversity and soil moisture under warming conditions. The change of soil moisture cannot affect plant growth significantly under warming conditions. Even an excessive increase in soil moisture caused by the thawing of permafrost would inhibit the growth of plants. Thus, soil moisture and species diversity might be negatively correlated under warming conditions. The longer the duration of the warming, the more obvious the negative correlation is.

Understanding the relationship between grassland biomass and soil microclimate factors should help reveal the mechanisms by which environmental factors affect the grassland biomass (Ma et al., 2010). This study found that warming decreased the positive correlation between aboveground biomass and soil temperature, which were significantly negatively correlated under the long-term warming. In the warming plots, soil moisture was positively correlated with aboveground biomass, but the correlation was weakened under the long-term warming. Huang et al. (2011) pointed out that aboveground biomass on the northern slope of Qilian Mountains was negatively correlated with soil temperature and significantly positively correlated with soil moisture. This is consistent with the conclusions of this study. Warming leads to a reduction in soil water content. In order to adapt to the water-stressed environment under the warming condition, plants need to improve their water use efficiency by reducing their biomass (Grime, 2001). Therefore, aboveground biomass was negatively correlated with soil temperature and positively correlated with soil moisture under the warming condition.

\section{Conclusions}

In this study, the effects of eight years of warming on aboveground biomass and species diversity of an alpine meadow on the QTP were studied. Warming changed the soil environment. In order to adapt to the warm and dry soil environment, plants made corresponding changes in their structure. In terms of aboveground biomass, warming led to a significant reduction in aboveground biomass of grasses and an increase in aboveground biomasses of sedges and weeds. This indicated that warming reduces the shallow soil moisture and promotes the growth of weeds, but is not conducive to the growth of grasses. Global climate warming thus alters the alpine meadow community structure and has a certain impact on the species diversity of the community. The short-term warming increased species diversity, whereas the long-term warming decreased species diversity, but not significantly. This suggested that the effects of eight years of warming on species diversity is relatively small, and a significant response of species diversity to warming may require a longer time scale. Warming did not significantly affect the relationship between soil microclimate factors and species diversity, while aboveground biomass and soil temperature were negatively correlated under the long-term warming. Global climate warming affects the structure and function of the alpine meadow ecosystem and has an important impact on the regional sustainable development. However, the current research on aboveground biomass and species diversity of an alpine meadow on the QTP is not conclusive. In addition to hydrothermal 
environmental factors, soil nutrients and biological characteristics of plants also affect species diversity and aboveground biomass of alpine meadows on the QTP, but the mechanisms of which need further exploration.

\section{Acknowledgements}

This study was financially supported by the National Natural Science Foundation of China (41501219), the Applied Basic Research Project of Shanxi Province (2016021136), the National College Students' Innovative Entrepreneurial Training Plan Program of China (201910119007), the Research Project of Philosophy and Social Sciences in Colleges and Universities of Shanxi Province (2019W134), and the Soft Science Research Project of Shanxi Province (2018041072-1). We thank LetPub (http://www.letpub.com) for its linguistic assistance during the preparation of this manuscript.

\section{References}

Alward R D, Detling J K, Milehunas D G. 1999. Grassland vegetation changes and nocturnal global warming. Science, 283(5399): 229-231.

Boeck H J, Lemmens C H, Gielen H, et al. 2007. Combined effects of climate warming and plant diversity loss on above- and below-ground grassland productivity. Environmental and Experimental Botany, 60(1): 95-104.

Grime J P. 2001. Plant Strategies, Vegetation Processes, and Ecosystem Properties (2 ${ }^{\text {nd }}$ ed.). New York: John Wiley and Sons, Ltd., 1-471.

Hautier Y, Seabloom E W, Borer E T, et al. 2014. Eutrophication weakens stabilizing effects of diversity in natural grasslands. Nature, 508(7497): 521-525.

Hautier Y, Tilman D, Isbell F, et al. 2015. Anthropogenic environmental changes affect ecosystem stability via biodiversity. Science, 348(6232): 336-340.

Hou Y H, Zhou G S, Xu Z Z. 2013. An overview of research progress on responses of grassland ecosystems to global warming based on infrared heating experiments. Chinese Journal of Plant Ecology, 37(12): 1153-1167. (in Chinese)

Huang D Q, Yu L, Zhang Y S, et al. 2011. Above-ground biomass and its relationship to soil moisture of natural grassland in the northern slopes of the Qilian Mountains. Acta Prataculturae Sinica, 20(3): 20-27. (in Chinese)

Jiang Y B, Fan M, Zhang Y J. 2017. Effect of short-term warming on plant community features of alpine meadow in Northern Tibet. Chinese Journal of Ecology, 36(3): 616-622. (in Chinese)

Kimball B A, Conley M M, Wang S, et al. 2007. Infrared heater arrays for warming ecosystem field plots. Global Change Biology, 14(2): 309-320.

Klein J A, Harte J, Zhao X Q. 2004. Experimental warming causes large and rapid species loss, dampened by simulated grazing, on the Tibetan Plateau. Ecology Letters, 7(12): 1170-1179.

Kudo G, Suzuki S. 2003. Warming effects on growth, production, and vegetation structure of alpine shrubs: A five-year experiment in northern Japan. Oecologia, 135(2): 280-287.

Li J R, Liu Z H. 2017. High-cold meadow plants respond to long-term warming. Qinhai Prataculture, 26(3): 13-18, 24. (in Chinese)

Li J X, Zhang Y J, Zhu J T, et al. 2019. Responses of community characteristics and productivity to a warming gradient in a Kobresia pygmaea meadow of the Tibetan Plateau. Acta Ecologica Sinira, 39(2): 474-485. (in Chinese)

Li N, Wang G X, Yang Y, et al. 2011. Short-term effects of temperature enhancement on community structure and biomass of alpine meadow in the Qinghai-Tibet Plateau. Acta Ecologica Sinica, 31(4): 895-905. (in Chinese)

Li Y N, Zhao L, Zhao X Q, et al. 2004. Effects of a 5-years mimic temperature increase to the structure and productivity of Kobresia humilis meadow. Acta Agrestia Sinica, 12(3): 236-239. (in Chinese)

Lin D L, Xia J Y, Wan S Q. 2010. Climate warming and biomass accumulation of terrestrial plants: A meta-analysis. New Phytologist, 188(1): 187-198.

Lu H, Cong J, Liu X, et al. 2015. Plant diversity patterns along altitudinal gradients in alpine meadows in the Three River Headwater Region, China. Acta Prataculturae Sinica, 24(7): 197-204. (in Chinese)

Ma L, Xu M H, Zhai D T, et al. 2017. Response of alpine meadow vegetation-soil system to climate change: A review. Chinese Journal of Ecology, 36(6): 1708-1717. (in Chinese)

Ma W H, Fang J Y, Yang Y H, et al. 2010. Biomass carbon stocks and their changes in northern China's grasslands during 1982 2006. Science China Life Sciences, 53(7): 841-850.

Ma Z Y, Liu H Y, Mi Z R, et al. 2017. Climate warming reduces the temporal stability of plant community biomass production. 
Nature Communications, 8(8): 15378, doi: 10.1038/ncomms 15378 .

Niu S L, Han X G, Ma K P, et al. 2007. Field facilities in global warming and terrestrial ecosystem research. Journal of Plant Ecology, 31(2): 262-271. (in Chinese)

Oliver T H, Isaac N J B, August T A, et al. 2015. Declining resilience of ecosystem functions under biodiversity loss. Nature Communications, 6(1): 10122, doi: 10.1038/ncomms10122.

Oreskes N. 2004. The scientific consensus on climate change. Science, 306(5702): 1686, doi: 10.1126/science.1103618.

Pauli H, Gottfried M, Grabherr G. 2001. High summits of the Alps in a changing climate. In: Walther G R, Burga C A, Edwards P J. "Fingerprints" of Climate Change: Adapted Behaviour and Shifting Species Ranges. New York: Kluwer Academic/Plenum Publishers, 139-149.

Peng F, Xue X, Xu M H, et al. 2017. Warming-induced shift towards forbs and grasses and its relation to the carbon sequestration in an alpine meadow. Environmental Research Letters, 12(4): 044010, doi: 10.1088/1748-9326/aa6508.

Prieto P, Penuelas J, Niinemets U, et al. 2009. Changes in the onset of spring growth in shrubland species in response to experimental warming along a north-south gradient in Europe. Global Ecology and Biogeography, 18(4): 473-484.

Qin D H, Thomas S. 2014. Highlights of the IPCC Working Group I Fifth Assessment Report. Climate Change Research, 10(1): 1-6. (in Chinese)

Qiu J. 2008. China: The third pole. Nature, 454(7203): 393-396.

Sandvik S M, Heegaard E, Elven R, et al. 2004. Responses of alpine snowbed vegetation to long-term experimental warming. Ecoscience, 11(2): 150-159.

Shi F S, Wu N, Luo P. 2008. Effect of temperature enhancement on community structure and biomass of subalpine meadow in northwestern Sichuan. Acta Ecologica Sinica, 28(11): 5286-5293. (in Chinese)

Shi Z, Sherry R, Xu X, et al. 2015. Evidence for long-term shift in plant community composition under experimental climate warming. Journal of Ecology, 103(5): 1131-1140.

Walker M D, Wahren C H, Hollister R D, et al. 2006. Plant community responses to experimental warming across the tundra biome. Proceedings of the National Academy of Sciences of the United States of America, 103(5): 1342-1346.

Wan S Q, Luo Y Q, Wallace L L. 2002. Changes in microclimate induced by experimental warming and clipping in tallgrass prairie. Global Change Biology, 8(8): 754-768.

Wang C S, Meng F D, Li X E, et al. 2013. Responses of alpine grassland ecosystem on Tibetan Plateau to climate change: A mini review. Journal of Ecology, 32(6): 1587-1595. (in Chinese)

Wang Y H, Zhou G S. 2004. Responses of temporal dynamics of aboveground net primary productivity of Leymus chinensis community to precipitation fluctuation in Inner Mongolia. Acta Ecologica Sinica, 24(6): 1140-1145. (in Chinese)

Welker J M, Molau U, Parsons A N, et al. 1997. Responses of Dryas octopetala to ITEX environmental manipulations: A synthesis with circumpolar comparisons. Global Change Biology, 3(S1): 61-73.

Wu J S, Li X J, Shen Z X. 2012. Species diversity distribution pattern of alpine grasslands communities along a precipitation gradient across northern Tibetan Plateau. Acta Prataculturae Sinica, 21(3): 17-25. (in Chinese)

Wu S H, Yin Y H, Zheng D, et al. 2005. Climate changes in the Tibetan Plateau during the last three decades. Acta Geographica Sinica, 60(1): 3-11. (in Chinese)

Xu M H, Xue X. 2013. A research on summer vegetation characteristics \& short-time responses to experimental warming of alpine meadow in the Qinghai-Tibetan Plateau. Acta Ecologica Sinica, 33(7): 2071-2083. (in Chinese)

Xu M H, Liu M, Xue X, et al. 2015a. Effects of warming and clipping on the growth of aboveground vegetation in an alpine meadow. Ecology and Environmental Sciences, 24(2): 231-236. (in Chinese)

Xu M H, Peng F, You Q G, et al. 2015b. Effects of warming and clipping on plant and soil properties of an alpine meadow in the Qinghai-Tibetan Plateau, China. Journal of Arid Land, 7(2): 189-204.

Xu M H, Liu M, Xue X, et al. 2016. Warming effects on plant biomass allocation and correlations with the soil environment in an alpine meadow, China. Journal of Arid Land, 8(5): 773-786.

Xu M H, Li X L, Liu M, et al. 2020. Spatial variation patterns of plant herbaceous community response to warming along latitudinal and altitudinal gradients in mountainous forests of the Loess Plateau, China. Environmental and Experimental Botany, 172: 103983, doi: 10.1016/j.envexpbot.2020.103983.

Yang Y W, Li X L, Zhou X H, et al. 2016. Study on relationship between plant community degradation and soil environment in an alpine meadow. Acta Agrestia Sinica, 24(6): 1211-1217. (in Chinese)

Yang Z L, Zhang Q, Su F L, et al. 2017. Daytime warming lowers community temporal stability by reducing the abundance of dominant, stable species. Global Change Biology, 23(1): 154-163.

Yin H J, Lai T, Cheng X Y, et al. 2008. Warming effects on growth and physiology of seedlings of Betula albo-sinensis and Abies faxoniana under two contrasting light conditions in subalpine coniferous forest of Western Sichuan, China. Journal of 
Plant Ecology, 32(5): 1072-1083. (in Chinese)

Zhao T Q, Ouyang Z Y, Zheng H, et al. 2004. Analyses on grassland ecosystem services and its indexes for assessment. Chinese Journal of Ecology, 23(6): 155-160. (in Chinese)

Zhao X Q, Chen S L, Cao G M, et al. 2003. Study on interacting mechanisms of alpine meadow ecosystem with global change in Tibetan Plateau. Technology and Industry, 3(8): 51-59. (in Chinese)

Zhao Y Y, Zhou H K, Yao B Q, et al. 2015. The influence of long-term simulating warming to the plant community and soil nutrient of alpine meadow. Acta Agrestia Sinica, 23(4): 665-671. (in Chinese)

Zhou H K, Zhou X M, Zhao X Q. 2000. A preliminary study of the influence of simulated greenhouse effect on a Kobresia humilis meadow. Acta Phytoecologica Sinica, 24(5): 547-553. (in Chinese)

Zong N, Chai X, Shi P L, et al. 2016. Responses of plant community structure and species composition to warming and N addition in an alpine meadow, northern Tibetan Plateau, China. Chinese Journal of Applied Ecology, 27(12): 3739-3748. (in Chinese) 